\title{
Caracterização da germinação e morfologia de frutos, sementes e plântulas de Dalbergia cearensis Ducke (pau-violeta) - Fabaceae
}

\author{
Francisco Carlos Barboza Nogueira ${ }^{1,4}$, Sebastião Medeiros Filho² e Maria Izabel Gallão ${ }^{3}$
}

Recebido em 18/05/2010. Aceito em 05/10/2010

\begin{abstract}
RESUMO - (Caracterização da germinação e morfologia de frutos, sementes e plântulas de Dalbergia cearensis Ducke (pau-violeta) - Fabaceae). Este estudo teve como objetivo descrever e ilustrar as características morfológicas de frutos, sementes, fases iniciais da germinação e plântulas de Dalbergia cearensis aos 28 dias após semeadura. O fruto, sustentado por estipe de $3 \mathrm{a} 5 \mathrm{~mm}$, é seco, indeiscente, do tipo sâmara, oblongo, de ápice e base agudos, monospérmico, plano, com núcleo seminífero central, pericarpo tênue, aliforme, levemente reticulado. A Semente é exalbuminosa, oblonga, achatada, reniforme, com testa lisa, opaca, apresentando, quando madura, coloração acastanhada de tonalidade clara. A germinação é do tipo epígea com o tegumento aderido aos cotilédones na fase inicial do crescimento da plântula e tem início a partir do terceiro dia após a semeadura, em condições de laboratório. Verificou-se um percentual médio de germinação de $70 \%$, aos 14 dias. Aos 28 dias de semeadura a plântula apresenta sistema radicular axial, raiz principal pivotante longa com 231,54 mm de comprimento, cilíndrica, flexível, branco-amarelada. As plântulas são classificadas no tipo morfofuncional faneroepígeo-armazenador (PER).
\end{abstract}

Palavras-chave: Biometria, crescimento inicial, jacarandá-violeta, espécie nativa, sementes florestais

ABSTRACT - (Morphological characterization of fruits, seeds, seedlings and germination of Dalbergia cearensis Ducke - Fabaceae). This study describes and illustrates the morphological characteristics of fruits, seeds, early stages of germination and seedlings of Dalbergia cearensis for the first 28 days after sowing. The fruit, which is supported by a 3-5 mm stipe, is a dry, indehiscent samara, oblong with acute base and apex, 1-seeded, flat, with a central seminiferous nucleus, thin pericarp, aliform, slightly reticulate. The seed is exalbuminous, oblong, flat, reniform, with a smooth seed coat; it is a brownish color when ripe. Germination is epigeous, with the tegument adhering to the cotyledons in the initial seedling growth phase; it begins on the third day after sowing in laboratory conditions. Mean germination of $70 \%$ was observed at 14 days. On day 28 after sowing, seedlings had an axial root system, a pivotal main root, $231.54 \mathrm{~mm}$ long, cylindrical, flexible, yellowish-white. The seedlings are classified as phanero-epigeal-reserve (PER) type.

Key words: Biometry, initial growth, kingwood, native species, forest seeds

\section{Introdução}

Atualmente, há um crescente interesse na caracterização morfológica de frutos, sementes e plântulas de espécies nativas (Amorim et al. 2006; Ramos \& Ferraz 2008; Paiva Sobrinho \& Siqueira 2008; Paoli \& Bianconi 2008; Cosmo et al. 2009). Os estudos morfológicos fornecem informações para a identificação botânica das espécies, auxiliam na interpretação dos testes de germinação em laboratório, orientam quanto ao armazenamento de sementes e métodos de cultivo, além de facilitarem o reconhecimento das espécies em banco de sementes no solo (Donadio \& Demattê 2000).

$\mathrm{Na}$ natureza, há uma expressiva variedade na forma e tamanho de frutos (Paoli \& Bianconi 2008). A descrição dos frutos, dentro de um contexto ecológico, representa um novo caminho para compreender a biologia da reprodução (Lima 1990). Além disso, características morfológicas de semente e fruto constituem critério bastante seguro para a identificação das plantas ao nível de espécie (Ramos \& Ferraz 2008). A descrição morfológica de plântulas auxilia estudos ligados à germinação e suas ilustrações fornecem subsídios para padronizar testes de germinação em laboratório (Silva et al.1995).

Além dos atributos morfológicos das sementes, frutos e plântulas, características dos cotilédones como tamanho, função e posição no desenvolvimento inicial de plântulas podem ser decisivos na captura de recursos ambientais, os quais podem contribuir para diminuição da mortalidade e aumentar o fitness (Ibarra-Manríquez et al. 2001). Este conjunto de características, que representa a morfologia inicial da germinação, recebeu atenção especial no sentido de compreender o significado ecológico da história de vida das plantas (Duke 1965; Duke \& Polhill 1981; Garwood 1983; Miquel 1987; Garwood 1996).

Esta pesquisa foi realizada com Dalbergia cearensis Ducke, da família Fabaceae, espécie característica da caatinga do Nordeste brasileiro, conhecida pelos nomes vulgares Brazilian kingwood, jacarandá-violeta, miolode-negro, pau-violeta e violeta (Carvalho 1997). Apresenta grande potencial econômico devido ao uso de sua madeira para diversos fins e destina-se a usos especiais, como fabricação de móveis, objetos de adorno, caixas e estojos entalhados, cabos de faca e objetos de decoração (Rizinni 1978).

Para compreender e ilustrar os aspectos morfológicos dos frutos, sementes e plântulas até 28 dias após semeadura, bem como caracterizar o processo de germinação de Dalbergia cearensis, pretende-se responder as seguintes questões: os frutos e sementes de pau-violeta apresentam variabilidade com relação às características biométricas e morfológicas? Qual a característica germinativa de suas sementes e qual é a característica de suas plântulas?

\footnotetext{
1 Universidade Federal do Ceará, Programa de Pós-Graduação em Ecologia e Recursos Naturais, Departamento de Biologia, Fortaleza, CE, Brasil

2 Universidade Federal do Ceará, Departamento de Fitotecnica, Fortaleza, CE, Brasil

3 Universidade Federal do Ceará, Departamento de Biologia, Fortaleza, CE, Brasil

4 Autor para correspondência: fcbnogueira@terra.com.br
} 


\section{Material e métodos}

Local de coleta e armazenamento - Frutos maduros de Dalbergia cearensis foram coletados manualmente no mês de agosto de 2009, de cinco árvores matrizes selecionadas ao acaso, localizadas em área de Unidade de Conservação de Uso Sustentável, situada na fazenda Não Me Deixes município de Quixadá, Ceará. A propriedade de 929 ha, teve em 1998, 300 ha reconhecidos como Reserva Particular do Patrimônio Natural - RPPN ( 4'49'34" S, 38 $38^{\circ}$ ' 9" W e $210 \mathrm{~m}$ de altitude) pelo Instituto Brasileiro do Meio Ambiente e dos Recursos Naturais Renováveis - IBAMA. A flora da propriedade foi descrita por Costa et al. (2007). O clima do município de Quixadá é classificado como Tropical Quente Semiárido, com pluviosidade média anual de $838,1 \mathrm{~mm}$, concentrada nos meses de fevereiro a abril, e temperatura média de $26^{\circ}$ a $28^{\circ} \mathrm{C}$ (Ipece 2005).

Ainda na fazenda, os frutos foram colocados para secar a pleno sol. Após a secagem, os frutos foram acondicionados em sacos de polietileno e conduzidos ao Laboratório de Análise de Sementes do Departamento de Fitotecnia do Centro de Ciências Agrárias, da Universidade Federal do Ceará - UFC. No Laboratório, com ajuda de estilete, se fez a extração das sementes manualmente. As sementes foram armazenadas em geladeira com temperatura média de $8^{\circ} \mathrm{C}$, por aproximadamente cinco meses, até o início dos tratamentos.

Biometria e descrição morfológica dos frutos e sementes - Para as determinações biométricas, após mistura e homogeneização, foram utilizados 100 frutos e 200 sementes, escolhidos ao acaso, para medição individual. Frutos e sementes foram pesados em balança analítica com precisão de $0,001 \mathrm{~g}$, mensurados quanto ao comprimento, largura e espessura utilizando-se um paquímetro digital, com precisão de $0,01 \mathrm{~mm}$. O comprimento foi medido da base até o ápice e a largura e espessura medidas na linha mediana dos frutos e sementes. Os dados das características quantitativas foram submetidos à análise descritiva, onde se calculou com ajuda do aplicativo Excel, média aritmética, desvio padrão, erro padrão, coeficiente de variação e intervalo de confiança. A determinação do número de sementes por quilograma e peso de 1.000 sementes foi realizada segundo recomendações das Regras para Análise de Sementes (Brasil 2009).

Nos frutos foram considerados os seguintes aspectos para a descrição: peso, tipo, cor, dimensões, textura e consistência do pericarpo e número de sementes por fruto. Nas sementes as características morfológicas externas observadas e descritas foram: cor, dimensões, textura e consistência dos tegumentos, forma, bordo, posição do hilo, da micrópila e rafe. As características internas consideradas foram: embrião (cotilédones, eixo hipocótilo-radícula, plúmula) e presença de endosperma. As sementes foram hidratadas para facilitar o estudo da morfologia interna.

Os métodos e termos empregados para descrever os aspectos morfológicos de frutos, sementes, germinação e plântulas de $D$. cearensis basearam-se nos trabalhos de Lima (1990), Beltrati (1994), Garwood (1996), Barroso et al. (1999) e Vidal \& Vidal (2003). Quanto ao modo de dispersão, o fruto foi classificado por sua morfologia conforme Van der Pijl (1972) e Barroso et al. (1999).

Teste de germinação - As sementes foram desinfetadas com hipoclorito de sódio a $20 \%$, por 20 minutos, e posteriormente lavadas em água corrente por 10 minutos, segundo método proposto nas Regras para Análise de Sementes (Brasil 2009), com modificação. Optou-se por adotar maior concentração de hipoclorito de sódio com menor tempo de exposição por se tratar de semente de espécie nativa com grande susceptibilidade ao ataque de fungos, como constatado em ensaio preliminar. O teste de germinação foi conduzido com 100 sementes em um delineamento inteiramente casualizado, com quatro repetições de 25 sementes. Estas foram colocadas para germinar em duas folhas de papel de filtro germitest, dispostas em placas de Petri de $14 \mathrm{~cm}$ de diâmetro, umedecidas com água destilada na proporção de 2,5 vezes o peso do papel. Quando necessário, as folhas eram reumedecidas. As placas de Petri foram acondicionadas em câmaras de germinação reguladas à temperatura de $25{ }^{\circ} \mathrm{C}$, com 12 horas de luz/12 de escuro. A avaliação da germinação foi diária, sendo consideradas sementes germinadas as que apresentaram emissão de radícula com $5 \mathrm{~mm}$.

Ao final do teste, que teve duração de 14 dias, foram determinados porcentagem de germinação, índice de velocidade de germinação e tempo médio de germinação. Foram consideradas normais as plântulas que alcançaram o estádio em que todas as estruturas essenciais foram precisamente verificadas. Plântulas consideradas anormais apresentaram cotilédones escuros e sem o sistema radicular desenvolvido ou com raiz primária deteriorada. As sementes mortas foram aquelas que no final do teste apresentaram-se amolecidas, atacadas por microorganismos (fungos) e não apresentaram nenhum sinal de início de germinação.

Morfologia do processo de germinação até plântula - A fim de acompanhar o desenvolvimento das plântulas, sementes foram semeadas em uma bandeja germinadora constituída por 67 células, com substrato de vermiculita. Considerou-se plântula, a fase compreendida entre a germinação da semente até a queda dos cotilédones. $\mathrm{O}$ crescimento das plântulas ocorreu em casa de vegetação coberta com sombrite $(50 \%$ de luz) e irrigação intermitente. Foram feitas avaliações diárias no período de 27/01/2010 (data da semeadura) a 24/02/2010. Para as descrições morfológicas e ilustração dos caracteres, foram utilizadas as plântulas que se apresentavam mais vigorosas. Entendendo-se como vigorosas aquelas plântulas com todas as suas estruturas essenciais bem desenvolvidas, completas e proporcionais. Os elementos vegetativos descritos e ilustrados foram raízes principal e secundárias, colo, hipocótilo, cotilédones, epicótilo e protófilos. As ilustrações foram realizadas manualmente a olho nu.

Para as medidas de produção de massa fresca e seca foram selecionadas 30 plântulas com crescimento uniforme, 28 dias após a semeadura. As plântulas foram lavadas para ficarem livres da vermiculita, e efetuou-se a medida do diâmetro do colo, tamanho da raiz, parte aérea (hipocótilo + epicótilo), número de folhas e número de folíolos. As folhas, caule e raiz foram separados para medição do peso úmido e, após esta medição, foram depositados em sacos de papel e mantidos em estufa a $70{ }^{\circ} \mathrm{C}$ até o peso manter-se constante. Para obtenção dos pesos seco e úmido utilizou-se balança com precisão de $0,01 \mathrm{~g}$. Os dados foram submetidos à análise descritiva, onde com o uso do aplicativo Excel se calculou média aritmética e desvio padrão.

Classificação de tipos de plântulas - Os critérios pré-estabelecidos para caracterizar tipos de anormalidade nas plântulas seguiram as Regras para Análise de Sementes (Brasil 2009). Plântulas foram classificadas de acordo com a posição (comprimento do hipocótilo), exposição (cotilédones cobertos ou descobertos pelos envoltórios da semente) e função (cotilédones de reserva ou fotossintetizantes), segundo classificação proposta por Garwood (1996). Os termos epígea e hipógea se referem à posição dos cotilédones acima do nível do solo ou abaixo, respectivamente. Os termos fanerocotiledonar e criptocotiledonar se referem a exposição dos cotilédones livres ou encerrados no interior dos envoltórios da semente, respectivamente. Os cotilédones podem ser carnosos (função de reserva) ou foliáceos (fotossíntese). As plântulas foram classificadas de acordo com Garwood (1996), com base nas características dos cotilédones e comprimento do hipocótilo.

\section{Resultados e discussão}

Biometria do fruto e da semente - Os frutos de D. cearensis não apresentam uniformidade quanto ao tamanho. $\mathrm{O}$ comprimento do fruto variou entre 30,61 a $47,57 \mathrm{~mm}$, a largura entre 7,83 a $10,88 \mathrm{~mm}$ e espessura entre 2,94 a $4,95 \mathrm{~mm}$. O peso dos frutos variou de 100 a $177 \mathrm{mg}$. Na Tab.1 são apresentados os valores médios referentes ao comprimento $(38,62 \mathrm{~mm})$, largura $(9,79 \mathrm{~mm})$, espessura $(3,99 \mathrm{~mm})$ e peso $(144,59 \mathrm{mg})$ para os frutos de $D$. cearensis. As freqüências dos comprimentos, largura, espessura e peso, podem ser observadas nas Fig. 1A-D, com as respectivas médias. De acordo com Rizzini (1978) o fruto dessa espécie apresenta medidas que variam entre 30 a $40 \mathrm{~mm}$ de comprimento e 15 a $20 \mathrm{~mm}$ de largura. Lima (1990) descreveu a sâmara de Dalbergia com 20 a $80 \mathrm{~mm}$ de comprimento e 10 a $25 \mathrm{~mm}$ de largura.

As diferenças em tamanho dos frutos de $D$. cearensis encontrada por Rizzini (1978) e descrita por Lima (1990) para a tribo Dalbergieae, e os observados neste estudo, podem estar relacionadas à diversidade genética própria da espécie na po- 
Tabela 1. Média, desvio padrão, erro padrão, coeficiente de variação e intervalo de confiança (IC) referentes às determinações biométricas (comprimento, largura e espessura) e peso em uma amostra de 100 frutos de Dalbergia cearensis Ducke.

\begin{tabular}{|c|c|c|c|c|c|}
\hline Variável & Média & Desvio Padrão & Erro Padrão & $\begin{array}{l}\text { Coeficiente de } \\
\text { variação }\end{array}$ & IC $95 \%$ \\
\hline Comprimento (mm) & 38,62 & 2,95 & 0,3 & 7,64 & $38,62 \pm 0,57$ \\
\hline Largura (mm) & 9,79 & 0,55 & 0,06 & 5,65 & $9,79 \pm 0,10$ \\
\hline Espessura (mm) & 3,99 & 0,38 & 0,04 & 9,5 & $3,99 \pm 0,07$ \\
\hline Peso dos frutos (mg) & 144,59 & 15,01 & 1,5 & 10,38 & $144,59 \pm 2,94$ \\
\hline Número de sementes & 1 & & & & \\
\hline
\end{tabular}
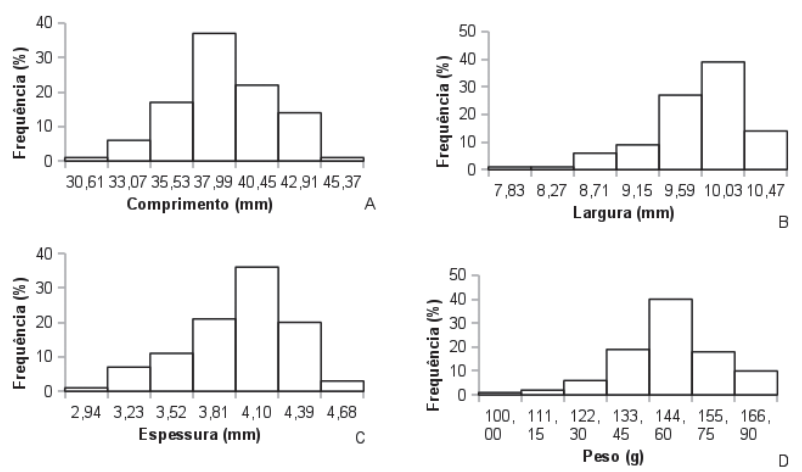

Figura 1. Frequências dos comprimentos, largura, espessura e peso de frutos de Dalbergia cearensis.

pulação. Condições de estresse hídrico ocasionado pela seca desencadeiam em espécies da caatinga alterações funcionais. Dentre as quais, modificações anatomo-morfológicas que incluem aprofundamento do sistema radicular, diminuição no tamanho da folha, expansão caulinar e perda de folhas (Trovão et al. 2007). Assim, acredita-se que a modificação em tamanho de frutos esteja não apenas relacionada ao patrimônio genético, mas às condições determinadas pelo meio ambiente.

Assim como observado nos frutos, as sementes mostraram diferença no tamanho apresentando variação no comprimento $(5,67$ a $11,81 \mathrm{~mm})$, largura $(3,98$ a 5,73 $\mathrm{mm})$ e espessura (1,41 a 3,39 mm). O peso das sementes variou de $37 \mathrm{mg}$ a $97 \mathrm{mg}$. Os valores médios atribuídos ao comprimento, largura, espessura e peso das sementes foram, respectivamente, 7,91 $\mathrm{mm}, 4,81 \mathrm{~mm}, 2,44 \mathrm{~mm}$ e 71,20 $\mathrm{mg}$ (Tab. 2). As freqüências dos comprimentos, largura, espessura e peso, podem ser observados nas Fig. 2A-D, com as respectivas médias. Estes valores estão diferem dos descritos por Lima (1990) para as sementes da tribo Dalbergieae, 14 a $20 \mathrm{~mm}$ de comprimento e 6 a $11 \mathrm{~mm}$ de largura. O peso de 1.000 sementes foi de $58,50 \mathrm{~g}$, com $10,70 \%$ de umidade, o que permite inferir que em um quilograma de sementes de D. cearensis pode conter 17.094 sementes.

Há uma tendência no sentido de assumir que sementes são estáveis em proporção de massa, comparadas a outros órgãos menos plásticos da planta (Clavijo 2002). Não obstante, variação na massa de sementes ocorre em muitas espécies de plantas e, com freqüência, na própria planta (Vaughton \& Ramsey 1998). Sendo que essas variações de tamanho de sementes existentes na própria planta, não são provocadas por diferenças genéticas, mas são decorrentes dos efeitos do meio ambiente durante o seu desenvolvimento (Leishman et al. 2000). No entanto, as plantas deveriam abastecer todas as sementes por igual e alterar o número de sementes ao invés da massa, quando os níveis de recursos variam. A massa de semente ideal é aquela que maximiza o retorno por investimento de unidade. Sementes abaixo do tamanho ótimo terão baixo fitness, enquanto aquelas maiores que o ótimo desperdiçam recursos que poderiam ser usados para abastecer mais descendentes (Vaughton \& Ramsey 1998).

$\mathrm{Na}$ maioria dos habitats, o tamanho de sementes varia de dez ordens de magnitude, embora dentro da mesma espécie esse tamanho represente menos da metade dessa variação (Leishman et al. 2000). Espécies com grandes sementes apresentam maior persistência e estabelecimento sobre ampla faixa de condições ambientais, enquanto espécies com sementes de tamanho pequeno são mais dependentes de perturbação (Burke \& Grime 1996). Grandes sementes aumentam a sobrevivência de plântulas, porém, para essa relação ser compreendida se faz necessário entender como as reservas da semente são utilizadas durante a germinação e estabelecimento inicial da plântula (Kitajima \& Fenner 2000).

Tabela 2. Média, desvio padrão, erro padrão coeficiente de variação e intervalo de confiança referentes às determinações biométricas em uma amostra de 200 sementes de Dalbergia cearensis Ducke.

\begin{tabular}{|c|c|c|c|c|c|}
\hline Variável & Média & Desvio padrão & Erro padrão & C.V.(\%) & IC (95\%) \\
\hline Comprimento (mm) & 7,91 & 0,90 & 0,60 & 11,41 & $7,91 \pm 0,12$ \\
\hline Largura $(\mathrm{mm})$ & 4,81 & 0,32 & 0,02 & 6,70 & $4,81 \pm 0,04$ \\
\hline Espessura (mm) & 2,44 & 0,35 & 0,03 & 14,51 & $2,44 \pm 0,04$ \\
\hline Peso (mg) & 71,20 & 12,13 & 0,86 & 0,03 & $71,20 \pm 1,68$ \\
\hline
\end{tabular}



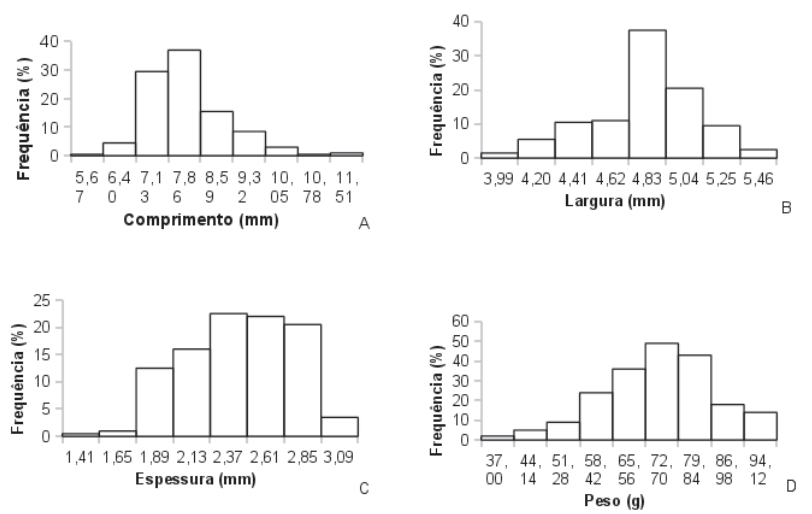

Figura 2. Frequências dos comprimentos, largura, espessura e peso de sementes de Dalbergia cearensis

O peso da semente representa uma forte influência no estabelecimento da planta, com sementes mais pesadas exibindo, frequentemente, maior comprimento inicial de plântulas e melhor sobrevivência sob pouca luz (Parker et al. 2006). Por outro lado, para Harper et al. (1970) sementes pequenas têm maior facilidade em obter água para germinação do que sementes grandes, devido à maior razão superfície/volume. Sementes de $D$. cearensis por serem pequenas apresentam uma característica vantajosa para as condições semiáridas do Nordeste brasileiro, uma vez que a disponibilidade de água está reduzida a uma curta estação chuvosa.

Morfologia do fruto e modo de dispersão - Conforme se observa na Fig. 3, o fruto tipo sâmara de $D$. cearensis é oblongo, apresenta pericarpo tênue de aspecto aliforme, seco, plano com exceção no centro devido a presença da semente, monospermo, indeiscente, levemente reticulado, com base e ápice agudos, sustentado por estipe de 3 a $5 \mathrm{~mm}$.
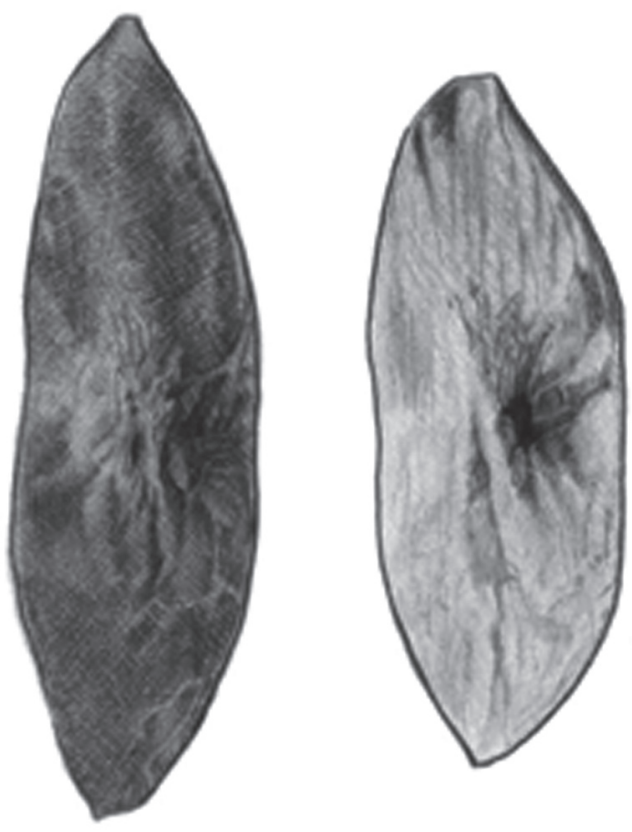

Figura 3. Frutos tipo sâmara de D. cearensis Ducke.
Externamente, o pericarpo, quando imaturo, é verde claro e, quando maduro acastanhado de tonalidade clara a escura. $\mathrm{O}$ fruto originário de ovário monocarpelar apresenta expansão em formato de asa ao redor da semente, com capacidade para planar pelo menos a curta distância. De acordo com Van der Pijl (1972) sâmaras de espécies de Dalbergia apresentam asa circular ao redor da vagem. Para Barroso et al. (1999) a morfologia do fruto alado tipo sâmara está relacionada como uma adaptação à dispersão anemocórica.

Lima (1990) descreve duas variações de sâmaras na tribo Dalbergieae: a primeira com núcleo seminífero indistinto da ala e apresenta uma delimitação entre a ala e o local onde se insere a semente, a qual está sempre localizada na região central do pericarpo (legume samaróide, sensu Barroso et al. 1999); e a segunda com núcleo seminífero distinto da ala, que, neste caso, pode ter uma posição apical, basal, circular ou nas laterais do fruto (sâmara, sensu Barroso et al. 1999). Segundo Queiroz (2009), os frutos alados ou sâmaras que ocorrem no gênero Dalbergia apresentam núcleo seminífero central e ala marginal.

A característica estrutural do fruto de $D$. cearensis, mostrou-se semelhante à descrita por Carvalho (2004) para Dalbergia brasiliensis Vogel, com sâmara monosperma, membranácea e oblonga. O fruto do jacarandá-da-bahia (Dalbergia nigra (Vell.) Fr. All.ex. Benth) foi descrito por Braz et al. (2009) como um legume samaróide, indeiscente, seco, com coloração marrom escura, superfície rugosa e brilhante, oblongo, com 1 a 2 sementes por fruto, a maioria monospérmicos. Barroso et al. (1999) afirmaram que as sâmaras são encontradas principalmente entre os componentes da tribo Dalbergieae e que sua descrição morfológica se sobrepõe às características florais em importância na descrição dessa tribo.

Griz \& Machado (2001) descreveram o comportamento de espécies da caatinga com relação ao modo de dispersão durante as estações seca e chuvosa. Relataram que as espécies anemocóricas são facilmente disseminadas pelo vento devido à estrutura dos diásporos em forma de asas que favorece sua queda em diagonal, aumentando a distância de dispersão da planta-mãe.

O fruto tipo sâmara da $D$. cearensis possui características de dispersão anemocórica e este fato pode facilitar uma dispersão a longas distâncias da planta-mãe. Isto pode ser vantajoso para a espécie em estudo, pois, pode permitir que as unidades dispersas a longa distância não sejam alvo de patógenos e predadores resultando em maiores chances de sobrevivência para as plântulas. A dispersão a longa distância permite os diásporos escaparem da alta mortalidade próxima à planta-mãe, onde predação, abundância de patógenos e competição intraespecífica são altas (Janzen 1970).

Descrição morfológica da semente - A semente de D. cearensis é exalbuminosa, oblonga, achatada, reniforme, com testa lisa, quando madura apresenta coloração acastanhada de tonalidade clara a escura, sem brilho. Hilo e micrópila não são visíveis a olho nu, localizados na região basal. Micrópila 
inconspícua, calaza pouco distinta e rafe ventral. Embrião curto e curvo, de coloração amarela clara e evidente entre os cotilédones, na parte interna. Plúmula pluripartida. Cotilédones crassos, elipsóides, opostos, sésseis, de coloração amarela leitosa, encontrando-se dispostos paralelamente ao eixo hipocótilo-radícula. Apresenta heterogeneidade de forma e tamanho (Fig. 4), discordando de Nakamura \& Oliveira (2005), que afirmaram que as sementes da tribo Dalbergieae são muito homogêneas, como em geral ocorre em frutos indeiscentes, motivo de não fornecerem subsídios importantes à sistemática do grupo. Porém, em Dalbergia nigra, as sementes planas, com hilo bem demarcado, com micrópila pequena e rafe situada na parte ventral (Braz et al. 2009), podem ser utilizadas na distinção desta espécie e de $D$. cearensis.
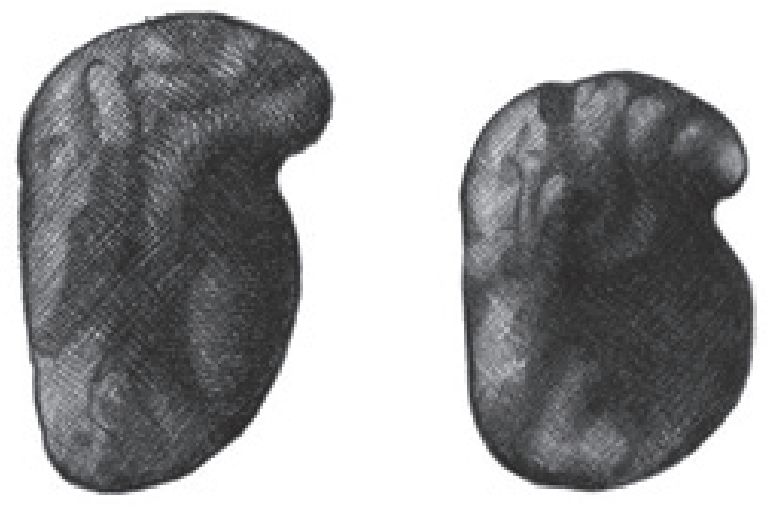

Figura 4. Aspectos morfológicos da semente de D. cearensis Ducke.

Variações na forma, cor e tamanho de sementes foram documentadas para algumas espécies da caatinga (Barbosa 2008; Araújo et al. 2007). Todavia, para Araújo et al. (2007), a pouca informação sobre estudos descritivos acerca das variações morfológicas das sementes da caatinga, impossibilita uma discussão mais ampla sobre a importância destas variações para o sucesso da germinação das sementes e do estabelecimento das plântulas.

Aspectos da germinação - A germinação da semente de $D$. cearensis é do tipo epígea com o tegumento aderido aos cotilédones na fase inicial do crescimento da plântula, forma mais comum de germinação encontrada na maioria das leguminosas, conforme Duke \& Polhill (1981). Tem início a partir do terceiro dia após a semeadura. A radícula rompe o tegumento na base apresentando-se curta, glabra, de cor branca e ápice pontiagudo. A raiz primária apresenta rápido desenvolvimento, inicialmente grossa, passando a fina com dilatação na base; cilíndrica, tenra, esbranquiçada e com coifa amarelada. O hipocótilo é inicialmente curvado até tornar-se reto (a partir do oitavo dia de semeadura), longo, cilíndrico, tenro, glabro, de coloração verde clara. As primeiras raízes secundárias nascem imediatamente abaixo do colo, que é bem evidenciado pelo maior diâmetro do hipocótilo. Cotilédones de reserva persistem por 27 a 29 dias na plântula, elípticos, verdes, opostos, sésseis, de consistência carnosa. Epicótilo tenro, cilíndrico, verde, glabro e em seu ápice acha-se a plúmula no início de seu desenvolvimento (Fig. 5).

$\mathrm{Na}$ Tab. 3 são apresentados a análise descritiva dos dados correspondentes a porcentagem de germinação $(\% \mathrm{G})$, o índice de velocidade de germinação (IVG), o tempo médio de germinação (TMG), sementes mortas, plântulas anormais e plântulas normais.

Verificou-se um percentual médio de germinação de $70 \%$, aos 14 dias. O processo germinativo foi relativamente rápido, iniciando-se após três dias de semeadura. Resultado semelhante foi obtido por Braz et al. (2009), para sementes

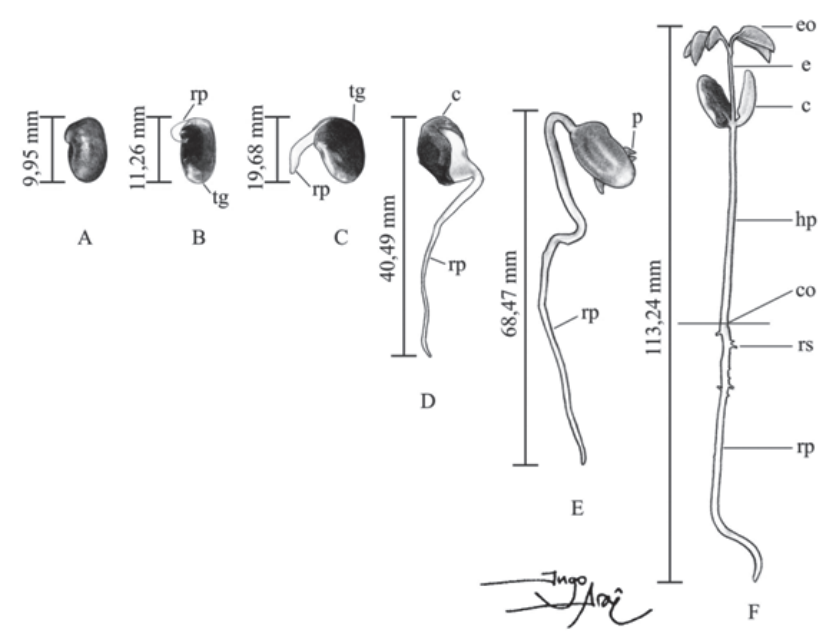

Figura 5. Aspectos morfológicos da germinação fanerocotiledonar-epígeaarmazenadora (PER) de Dalbergia cearensis Ducke : A - semente embebida e início da ruptura do tegumento (03 dias); B - plântula com 04 dias , tg - tegumento, rp - raiz primária; $\mathrm{C}$ - plântula com 05 dias; $\mathrm{D}$ - plântula com 06 dias, e - cotilédones; E - plântulas com 07 dias, $\mathrm{p}$ - protófilo; $\mathrm{F}$ - plântula com 10 dias, rp - raiz primária, rs - raiz secundária, co - colo, hp - hipocótilo, c - cotilédone, e - epicótilo, eo - eófilos.

Tabela 3. Porcentagem de germinação (\%G), índice de velocidade de germinação (IVG), tempo médio de germinação (TMG), sementes mortas, plântulas anormais e plântulas normais de Dalbergia cearensis Ducke, aos 14 dias após a germinação.

\begin{tabular}{|c|c|c|c|c|c|c|}
\hline Parâmetros & $\% \mathrm{G}$ & IVG & TMG & Sementes Mortas & Plântulas Normais & Plântulas Anormais \\
\hline Média & 70 & 2,37 & 6,86 & 7 & 16 & 2 \\
\hline Desvio Padrão & 7,66 & 0,26 & 0,51 & 2,58 & 1,50 & 1,26 \\
\hline Coeficiente de variação & 10,84 & 9,40 & 7,43 & 36,89 & 9,52 & 55,92 \\
\hline Erro padrão da média & 3,83 & 0,13 & 0,25 & 1,29 & 0,75 & 0,63 \\
\hline
\end{tabular}


de Dalbergia nigra, que germinaram aos três dias, contudo atingiram os 15 dias com $80 \%$ de germinação. Carvalho (2004) observou para Dalbergia brasiliensis um poder germinativo variável, de $13 \%$ a $86 \%$, com início entre 11 a 60 dias após a semeadura.

Espera-se que a germinação rápida seja vantajosa para espécies vegetais que precisam se estabelecer aproveitando as condições ambientais favoráveis, que na região de caatinga do Nordeste brasileiro, pode ser a ocorrência das primeiras chuvas. Barbosa (2008) reuniu dados sobre a biologia da reprodução e do crescimento de espécies lenhosas da caatinga com germinação rápida. Esta autora achou vantajoso o fato das espécies analisadas apresentarem maior percentual de germinação dentro do menor intervalo de tempo, pois permite que as sementes ou unidades de dispersão escapem dos predadores e ofereçam maiores chances de sobrevivência para as plantas.

Morfologia da plântula - Aos 28 dias de semeadura a plântula apresenta sistema radicular axial, raiz principal pivotante longa, com 231,54 mm de comprimento, cilíndrica, flexível, brancoamarelada. O colo é bem definido pela diferença de cor entre o hipocótilo e a raiz, pela redução de diâmetro do hipocótilo e pela dilatação apresentada nesta região. Raízes são finas, curtas, cilíndricas, da mesma cor da raiz primária. Posteriormente, a raiz primária passa à sublenhosa, de coloração marrom. $\mathrm{O}$ hipocótilo é longo, com 33,34 mm de comprimento e $0,91 \mathrm{~mm}$ de diâmetro, cilíndrico, verde, glabro, ereto. Os cotilédones são verdes, carnosos, espessos, opostos, sésseis, com 10,12-11,77 $\mathrm{mm}$ de comprimento e 4,26-5,23 mm de largura. Com 27 a 29 dias da semeadura, os cotilédones perdem a cor verde, tornamse amarelos e caem. Protófilos compostos, imparipinados, com três folíolos, pecíolos de 9,12 mm de comprimento, folíolo com 19,94 mm de comprimento e 14,54 mm de largura, verdes em ambas as faces, opostos, ovóides, às vezes elípticos, bordo inteiro; nervura peninérvea, com nervura principal bem evidente, impressa em ambas as faces e nervuras secundárias pouco evidentes. Epicótilo alongado com 34,71 mm de comprimento e $0,71 \mathrm{~mm}$ de diâmetro. A gema apical surge antes da completa expansão dos protófilos (Fig. 6).

O crescimento das plântulas ao atingir os 28 dias de idade mostrou um comprimento médio de $108,47 \mathrm{~mm}$ para raiz, contrapondo-se ao comprimento médio de
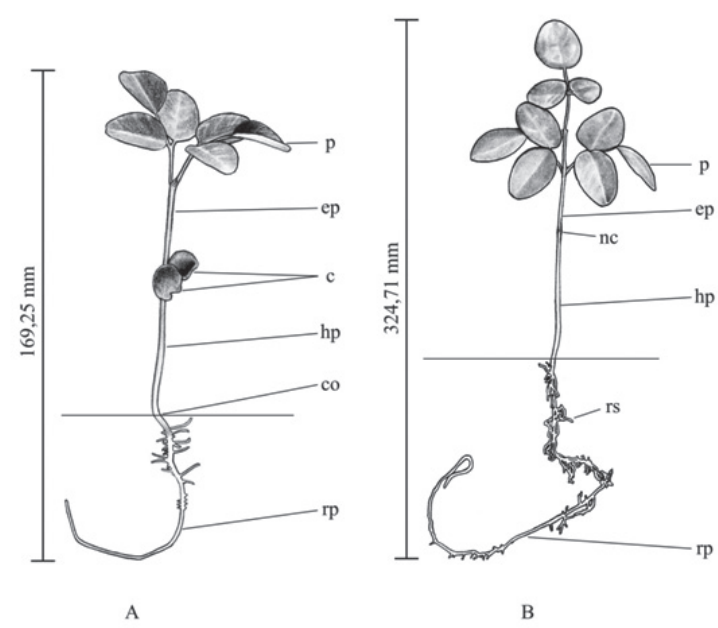

B

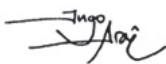

Figura 6. Aspectos morfológicos da plântula de D. cearensis Ducke aos 13 dias após a semeadura (A) e planta juvenil aos 31 dias, sem cotilédones (B). ( $\mathrm{rp}$ - raiz primária, co - colo, hp - hipocótilo, c - cotilédones, ep - epicótilo, $\mathrm{p}$ - protófilos, nc - nó cotiledonar).

$68,07 \mathrm{~mm}$ da parte aérea formado por caule e folhas. Isto representa um investimento de $1,84 \mathrm{~mm}$ de raiz para cada $1 \mathrm{~mm}$ de parte aérea. Por outro lado, ocorreu o inverso quando se analisou o peso seco acumulado na raiz e na parte aérea. A razão raiz/parte aérea foi igual a 0,20. Este valor mostra que para cada grama de investimento em raiz, a plântula investe cinco gramas de massa seca na parte aérea (Tab. 4 e 5).

Elevada razão raiz/parte aérea é uma característica relacionada às plantas sujeitas a estresse, em ambientes com acentuada estacionalidade climática (Ramos et al. 2004). Estes autores mostraram que Amburana cearensis, espécie típica de floresta estacional, se desenvolve melhor, em termos de acúmulo de massa seca e em variáveis alométricas, nas condições de pleno sol e até $50 \%$ de sombreamento. Contudo, fizeram uma avaliação ao longo de 16 meses, sendo prematuro prever este comportamento para $D$. cearensis, através de dados obtidos no período de 28 dias.

A morfologia de outras plântulas em Fabaceae como Dalbergia nigra, Hymenaea stigonocarpa Mart.ex Hayne, Dalbergia miscolobium Benth, Machaerium aculeatum

Tabela 4. Comprimento da raiz, parte aérea e razão comprimento da raiz/comprimento da parte aérea de Dalbergia cearensis Ducke, aos 28 dias de idade.

\begin{tabular}{ccccc}
\hline & Raiz $(\mathrm{mm})$ & \multicolumn{2}{c}{ Parte aérea $($ caule+folhas) $(\mathrm{mm})$} & Raiz/parte aérea $(\mathrm{mm})$ \\
\hline Média & Desvio padrão & Média & Desvio padrão & Média \\
108,47 & 59,09 & 68,07 & 11,86 & 1,84 \\
\hline
\end{tabular}

Tabela 5. Peso seco (g) da raiz, parte aérea e razão peso seco da raiz/peso seco da parte aérea de de Dalbergia cearensis Ducke, aos 28 dias de idade.

\begin{tabular}{ccccc}
\hline & Raiz $(\mathrm{g})$ & Parte aérea (caule+folhas) $(\mathrm{g})$ & Raiz/parte aérea $(\mathrm{g})$ \\
Média & Desvio padrão & Média & Desvio padrão & Média \\
0,01 & 0,01 & 0,05 & 0,01 & 0,20 \\
\hline
\end{tabular}


Raddi, Machaerium acutifolium Mart. Ex Benth também é epígea fanerocotiledonar (Donadio \& Demattê 2000; Botelho et al. 2000; Ressel et al. 2004 ) característica semelhante à encontrada em $D$. cearensis.

Plântulas de $D$. cearensis são classificadas como epígeas, por erguerem seus cotilédones acima do nível do solo, e fanerocotiledonares, por possuírem cotilédones carnosos, espessos que funcionam como órgãos de reserva. Efetivamente, os frutos e as sementes de $D$. cearensis apresentam variabilidade nas suas características biométricas. As sementes apresentam variação na forma mais acentuada do que os frutos, que são mais homogêneos. O processo germinativo é relativamente rápido, desuniforme, iniciando-se após três dias de semeadura. A germinação é fanerocotiledonarepígea-armazenadora (PER).

\section{Agradecimentos}

Os autores agradecem à Ingo Arerê Lima Barbosa pelas ilustrações. A Cássia Dias Pascoal do curso de Agronomia da Universidade Federal do Ceará pelo apoio às análises realizadas no Laboratório de Sementes da UFC. Ao Instituto Brasileiro do Meio Ambiente e dos Recursos Naturais Renováveis pela liberação em tempo integral do primeiro autor para realização do Doutorado em Ecologia e Recursos Naturais, no Departamento de Biologia da Universidade Federal do Ceará.

\section{Referências bibliográficas}

Amorim, I.L.; Ferreira, R.A.; Davide; A.C.\& Chaves. M.M.F. 2006. Aspectos morfológicos de plântulas e mudas de trema. Revista Brasileira de Sementes 28: 86-91.

Araújo, G.M.; Araújo, E.L.; Silva, K.A.; Ramos, E.M.N.F.; Leite, F.V.A. \& Pimentel, R.M.M. 2007. Resposta germinativa de plantas leguminosas da caatinga. Revista de Geografia 24: 139-153.

Barbosa, D.C.A. 2008. Estratégias de germinação e crescimento de espécies lenhosas da caatinga com germinação rápida. Pp. 625-656. In: Leal, I.R, Tabarelli, M. \& Silva, J.M.C (Eds). Ecologia e conservação da caatinga. Recife, Editora Universitária (UFPE).

Barroso, G.M.; Morim, M.P.; Peixoto, A.L. \& Ichaso, C.L.F. 1999. Frutos e sementes: morfologia aplicada à sistemática de dicotiledôneas. Viçosa, Editora UFV.

Beltrati,C.M. 1994. Morfologia e anatomia de sementes. Rio Claro, Departamento de Botânica da UNESP. Apostila do curso de PósGraduação em Biologia Vegetal.

Botelho, S.A.; Ferreira, R.A.; Malavasi. \& M.M.; Davide, A.C. 2000. Aspectos morfológicos de frutos, sementes, plântulas e mudas de jatobá-do-cerrado (Hymenaea stigonocarpa Mart.ex Hayne) Fabaceae. Revista Brasileira de Sementes 22: 144-152.

Brasil. 2009. Regras para análise de sementes. Brasília, Ministério da Agricultura, Pecuária e Abastecimento, Secretaria de Defesa Agropecuária.

Braz, M.S.S.; Souza, V.C.; Andrade, L.A.; Bruno, R.L.A.; Oliveira, L.S.B. \& Silva, J.M. 2009. Caracterização morfológica de frutos, sementes e plântulas de jacarandá-da-bahia (Dalbergia nigra (Vell.) Fr. All.ex. Benth) Leguminosae-Papilonoideae. Revista Brasileira de Ciências Agrárias 4: 67-71.

Burke, M.J.W. \& Grime, J.P.1996. An experimental study of plant community invisibility. Ecology 77: 776-790.

Carvalho, A.M. 1997. A synopsis of the genus Dalbergia (Fabaceae, Dalbergieae) in Brazil. Brittonia 49: 87-109.

Carvalho, P.E.R. 2004. Jacarandá - Dalbergia brasiliensis. Curitiba, Circular Técnica $n^{\circ} 98$, Embrapa.

Clavijo, E.R. 2002. Role of Within-individual Variation in Capitulum Size and Achene Mass in the Adaptation of the Annual Centaurea eriophora to Varying Water Supply in a Mediterranean Environment. Annals of Botany 90: 279-286
Cosmo, N.L.; Gogosz, A.M.; Nogueira, A.C.; Bona, C. \& Kuniyoshi, Y.S. 2009. Morfologia do fruto, da semente e morfo-anatomia da plântula de Vitex megapotamica (Spreng.) Moldenke (Lamiaceae). Acta Botanica Brasílica 23: 389-397.

Costa, R.C., Araújo,F.S. \& Lima-Verde, L.W. 2007. Flora and life-form spectrum in an area of deciduous thorn woodland (caatinga) in northeastern, Brazil. Journal of Arid Environments 68: 237-247.

Donadio, N.M.M. \& Demattê, M.E.S.P. 2000. Morfologia de frutos, sementes e plântulas de canafístula (Peltophorum dubium (Spreng) Taub.) e jacarandá-da-Bahia (Dalbergia nigra (Vell.) Fr. All. ex Benth.) - Fabaceae. Revista Brasileira de Sementes 22: 64-73.

Duke, J.A. \& Polhill, R.M. 1981. Seedlings of Leguminosae. Pp. 941-949. In: R.M. Polhill \& P.H. Raven (ed.). Advances in legume systematic, part 2. Kew, Royal Botanical Gardens.

Duke, J.A. 1965. Keys for the identification of seedlings of some prominent woody species in eight forest types in Puerto. Annals of the Missouri Botanical Garden 52: 314-350.

Garwood, N.C. 1983. Seed germination in a seasonal tropical forest in Panama: a community study. Ecological monographs 53: 159-181.

Garwood, N.C. 1996. Functional morphology of tropical tree seedlings. Pp. 59-129. In: Swaine, M.D. (ed.). The ecology of tropical forest tree seedlings. Paris, Unesco.

Griz, L.M.S. \& Machado, I.C.S. 2001. Fruiting phenology and seed dispersal syndromes in caatinga, a tropical dry forest in the northeast of Brazil. Journal of Tropical Ecology 17: 303-321.

Harper, J. L.; Lovel, P. H .\& Moore, K.G.1970. The shapes and sizes of seeds. Annual Review of Ecology and Systematics 1: 327-356.

Ibarra-Manríquez, G.; Ramos, M.M. \& Oyama, K. 2001. Seedling functional types in a lowland rain Forest in Mexico. American Journal of Botany 88: 1801-1812.

Ipece. 2005. Perfil básico municipal: Quixadá. Fortaleza, Governo do Estado do Ceará, Secretaria de Planejamento e Coordenação.

Janzen, D. H. 1970. Herbivores and the number of tree species in tropical forests. American Naturalist 104:501-528.

Kitajima, K. \& Fenner, M. 2000. Ecology of seedling regeneration.Pp. 331-359. In: Fenner, M (ed.). Seeds - the ecology of regeneration in plant communities. Wallingford, $\mathrm{CAB}$ International.

Leishman, M.R.; Wright, I.J.; Moles, A.T. \& Westoby, M. 2000. The evolutionary ecology of seed size. Pp. 31-57. In: Fenner, M (ed.). Seeds - the ecology of regeneration in plant communities. Wallingford, CAB International.

Lima, H.C. 1990. Tribo Dalbergieae (Leguminosae-Papilionoideae) - Morfologia dos frutos, sementes e plântulas e sua aplicação na sistemática. Arquivos do Jardim Botânico do Rio de Janeiro 30: $1-42$.

Miquel, S. 1987. Morphologie fonctionnelle de plantules d'espèces forestières du Gabon. Bulletin du Muséum National d' Histoire Naturelle 9:101-121.

Nakamura, A.T. \& Oliveira, D.M.T. 2005. Morfoanatomia e ontogênese da sâmara de Pterocarpus violaceus Vogel (Fabaceae: Faboideae). Revista Brasileira de Botânica 28: 375-387.

Paiva Sobrinho, S. \& Siqueira, A.G. 2008. Caracterização morfológica de frutos, sementes, plântulas e plantas jovens de mutamba (Guazuma ulmifolia Lam. - Sterculiaceae). Revista Brasileira de Sementes 30: $114-120$.

Paoli, A.A.S. \& Bianconi, A. 2008. Caracterização morfológica de frutos, sementes e plântulas de Pseudima frutescens (Aubl.) Radlk. (Sapindaceae). Revista Brasileira de Sementes 30: 146-155.

Parker, W.C.; Noland, T.L. \& Morneault, A.E. 2006. The effects of seed mass on germination, seedling emergence, and early seedling growth of eastern White pine (Pinus strobus L.). New Forests 32: 33-49.

Queiroz, L.P. 2009. Leguminosas da caatinga. Feira de Santana, UEFS.

Ramos, K.M.O.; Felfili, J.M.; Fagg, C.W.; Sousa-Silva, J.C. \& Franco, A.C. 2004. Desenvolvimento inicial e repartição de biomassa de Amburana cearensis (Allemao) A.C. Smith, em diferentes condições de sombreamento. Acta Botanica Brasilica 18: 351-358.

Ramos, M.B.P. \& Ferraz, I.D.K. 2008. Estudos morfológicos de frutos, sementes e plântulas de Enterolobium schomburgkii Benth. (Leguminosae-Mimosoideae). Revista Brasileira de Botânica 31: 227-235. 
Ressel, K.; Guilherme, F.A.G.; Schiavini, I. \& Oliveira, P.E. 2004. Ecologia morfofuncional de plântulas de espécies da Estação Ecológica do Panga, Uberlândia, Minas Gerais. Revista Brasileira de Botânica 27: 311-323

Rizzini, C.T. 1978. Árvores e madeiras úteis do Brasil - manual de dendrologia brasileira. Porto Alegre, Editora Edgard Blucher Ltda.

Silva, L.M.M.; Matos, V.P.; Pereira, D.D. \& Lima, A.A. 1995. Morfologia de frutos, sementes, e plântulas de Luetzelburgia auriculata Ducke (pau-serrote) e Pterogyne nitens Tul. (madeira-nova-do-brejo) Leguminosae. Revista Brasileira de Sementes 17: 154-159.
Trovão, D.M.B.M.; Fernandes, P.D.; Andrade, L.A. \& Dantas Neto, J. 2007. Variações sazonais de aspectos fisiológicos de espécies da caatinga. Revista Brasileira de Engenharia Agrícola e Ambiental 11: 307-311. Van der Pijl, L. 1982. Principles of dispersal in higher plants. New York, Springer Verlag.

Vaughton, G. \& Ramsey, M. 1998. Sources and consequences of seed mass variation in Banksia marginata (Proteaceae). Journal of Ecology 86:563-573.

Vidal, W.N. \& Vidal, M.R.R. 2003. Botânica-organografia:quadros sinópticos ilustrados de fanerógamos. Viçosa, Universidade Federal de Viçosa.

Versão eletrônica do artigo em www.scielo.br/abb e http://www.botanica.org.br/acta/ojs 